\title{
MODIFIED MSLQ: AN ANALYSIS OF ACADEMIC MOTIVATION, SELF-REGULATED LEARNING STRATEGIES, AND SCHOLASTIC PERFORMANCE IN INFORMATION SYSTEMS COURSES
}

\author{
Sheila M. Smith, Ball State University, smariesmith@bsu.edu \\ Catherine Chen, Ball State University, cchen@bsu.edu
}

\begin{abstract}
Motivational and self-regulated learning constructs have continued to pose vigorous, multi-dimensional questions for academicians. The challenge of aspiring students to elevate their social-cognitive perspective toward authentic learning, heightening the learners' interpretation of academic interactions, and articulating the role that their beliefs, cognitions, affects, and values play in scholastic performance is an evolving paradigm. The Motivational Strategies for Learning Questionnaire (MSLQ) has been used widely to assess students' general motivation to learn since 1991. Considering the learning approaches of new generation learning styles, this study modified statements in MSLQ, conducted validity tests, and investigated the relationship among academic motivation, self-regulated learning, and scholastic performance in university level information systems courses.
\end{abstract}

Keywords: MSLQ, motivation, self-regulated learning, scholastic performance, survey validation

\section{INTRODUCTION}

Collegiate management information systems courses constructed to teach computer literacy skills provide students with technical information and real-world application competencies that add value to information processing systems within business organizations. Possession of internal motivation and self-regulation learning strategies to learn computer literacy skills is a powerful resource sought by employers. Unfortunately, a skills gap perception exists between recent college graduates and employers. In 2016, CareerBuilder along with Economic Modeling Specialists Intl. (EMSI), a CareerBuilder company that provides industry-leading employment data and economic analysis via web tools and custom reports, commissioned a national Harris Poll survey of 2,300 employers, nearly half (49\%) of the employers expressed concern about the growing employment and skills gap in the U. S.

Employment Gap. The U.S. Census Bureau (2015) collapses management information systems degrees into the field of business; degrees in business have experienced stability during the past five years. Relative stability and growth of management information systems occupations is encouraging; unfortunately, the advancements are insufficient. Despite the conflicting reports of STEM supply and demand and the promising gains in degrees conferred in recent years, an overall employment gap exist (Auerbach, 2016). In the US, approximately 689,685 computer and technology jobs were posted, with an average number of hires of 209,035, leaving an employment gap of 480,650 computer and technology positions unfulfilled (Auerbach, 2016).

Skills Gap. The dearth in the supply of college graduates available to fulfill the growing demand for information technology professionals is a critical issue. In addition, management information executives in business are particularly concerned about the insufficiencies of college curriculums in computer and information systems programs. A 2015 AACU study found that while 46 percent of undergraduate students believed their technology skills were current and aligned with business needs, only 37 percent of employees believed students were well-prepared and possessed new technology skills relevant to business practices (Hart Research Associates, 2015).

Adding to the complexity of closing the employment and skills gap for computer and technology workers, is a new dilemma suggesting that the definition of science, technology, engineering, and math (STEM) has broaden to include a diverse body of academic majors and occupations (National Science Board, 2016). Therefore, research in the area of computer information systems should address academic success as it relates to self-regulated learning strategies to 
determine best practices that contribute to the sustainability of the information systems academic discipline and workforce placement.

\section{LITERATURE REVIEW}

Developed from social cognitive theory and cognitive development theory, self-regulated learning theory refers to how students master their own learning processes (Zimmerman \& Schunk, 2001; 2008). Self-regulated learning provides a strong theoretical framework that predicts academic success. The seminal work of Albert Bandura (1986; 1997) presented self-regulated learning (SRL) as a pivotal component of any major academic endeavor. Self-regulated learning is a central research area which provides explanations of academic success. Self-regulation affects motivation, emotions, selection of learning strategies, and effort regulation and leads to increases in self-efficacy, which in turns improves academic outcomes. SRL is a concept that emphasizes the active role of the learner in goal-setting and ensuring goal attainment in a college environment (Pintrich \& DeGroot, 1990; Pintrich \& Garcia, 1991).

Self-regulated learning refers to one's ability to understand and control one's learning environment. Self-regulation abilities include goal setting, self-monitoring, self-instruction, and self-reinforcement (Harris \& Graham, 1999; Schraw, Crippen, \& Hartley, 2006). Self-regulation does not equate to mental ability, but with the ability to engage in self-regulation processes that enable learners to transform mental abilities into skills (Zimmerman, Bonner \& Kovach, 2002) and developmental process behaviors (Butler, 1995, 1998, 2002) that materializes from practice and guidance (Paris \& Paris, 2001). Self-regulated learning strategies help learners prepare for the invaluable capacity to transfer skills, knowledge, and abilities from one domain or setting to another and for lifelong learning opportunities (Dinsmore, Alexander, \& Loughlin, 2008; Eccles, Wigfield, \& Schiefele, 1998).

Specifically, self-regulated learning consists of three components: (1) metacognition, (2) self-control, and (3) cognitive strategies. The goal of self-regulated learning is to increase awareness of these three strategies until they are automatically employed by the learner (Bransford, Brown, \& Cocking, 1999; Butler, 1995, 1998, 2002). Ideologies that affect the use and development of both the cognitive and metacognitive skills are delineated within the motivation component. Past research determined (Hackett \& Benz, 1989; Lent, Lopez, \& Blieschke, 1993) that the motivation component includes both self-efficacy (degree to which one is confident that one can perform a task or accomplish a goal) and epistemological beliefs (beliefs about the origin and nature of knowledge). Gottfried (1990) defines academic motivation as "enjoyment of school learning characterized by a mastery orientation; curiosity; persistence; task-value; and the learning of challenging, difficult, and novel tasks" (p. 525). In contrast, Turner (1995) considers motivation to be synonymous with cognitive engagement, which he defines as "voluntary uses of high-level selfregulated learning strategies, such as paying attention, connection, planning, and monitoring" (p. 413).

One of the most widely used instruments to assess students' use of learning strategies is the MSLQ. Based on a selfregulatory perspective on student motivation and learning, the questionnaire assesses student motivation and SRL in college students (Pintrich, Smith, Garcia, \& McKeachie, 1991). There are two sections in the MSLQ: a motivational section with six sub-scales and a learning strategies section with nine sub-scales. The MSLQ was designed with the flexibility to allow researchers to select sub-section or sub-scales for their research projects. Not only has this instrument been used in many disciplines, including education psychology, biology, social science, accounting, dietetics, and teaching education; it also has been translated into many languages, including Arabic, Chinese, Czech, Estonian, French, German, Japanese, Polish, Turkish, and many others.

Lynch (2010) found correlations between grades and intrinsic and extrinsic motivation and task value. Gender differences were found in this study, including the correlation between male, but not female, self-efficacy and course grades. Bīrcan and Sungur (2016) also found that self-efficacy was the best predictor of science achievement test; however, the findings revealed that cognitive engagement did not significantly predict students' achievement. The final grades were found correlated with elaboration in multiple studies (Lynch, 2010; Papantoniou et al., 2012). When accessing the relationship between learning strategies in information systems courses, research found that peer learning was negatively related to course grade (Niemczyk \& Savenye, 2001), critical thinking was negatively related to course graded (Chalupa, Chen, \& Charles, 2001; Niemczyk \& Savenye, 2001), and organization had an inverse relationship with course grade (Chalupa, Chen, \& Charles, 2001). 
Hashemyolia, Asmuni, Ayub, Daud, and Arif (2015) used the MSLQ among undergraduate science and social science students in Malaysia. Among the science and social science students, science possessed a significantly higher mean score for the students' effort regulation, task value, intrinsic goal orientation, and time management than social science students. This study suggested that student's motivation and use of learning strategies might be content based and vary in different subject areas.

Although MSLQ has been used successfully in accessing students' motivation and use of learning strategies for more than two decades, research had revealed concerns about the latent factor structure of the MSLQ. According to Hilpert, Stemien, van der Hoeven Kraft, and Husman (2013), the confirmatory factor analysis (CFA) did not produce a good fit in MSLQ's first development in 1990. An attempted was made to improve the fit in 1993 without success. Dunn, Lo, Mulvenon, and Sutcliffe, (2012) suggested further investigation to explore the latent factor structure of both motivation and learning strategies scales. Credé and Phillips (2011) conducted a meta-review of the MSLQ from 59 articles representing 19,900 college students and reported many relatively low validities for many of the MSLQ scales.

\section{PURPOSE OF THE STUDY}

The purpose of this study were to revise the MSLQ to access students' motivation and use of learning strategies in information systems courses and to investigate the relationship between academic motivation, self-regulated learning strategies, and scholastic performance in university-level information systems courses.

\section{RESEARCH METHODOLOGY}

This section describes the original scales in the MSLQ, the steps taken to revise the MSLQ items, the subjects participated in the study, the data collection procedures, the statistical analyses used, and the relationship between course grade and the scales in the revised MSLQ.

\section{The Original Scales}

The Motivation section of the original MSLQ consisted of 31 items in six scales: Intrinsic Goal Orientation, Extrinsic Goal Orientation, Task Value, Control of Learning Belief, Self-efficacy for Learning and Performance, and Test Anxiety. The Learning Strategies section consisted of 50 items in nine scales: Rehearsal, Elaboration, Organization, Critical Thinking, Metacognitive Self-Regulation, Time and Study Environment, Effort Regulation, Peer Learning, and Help Seeking (Pintrich et al., 1991).

\section{The Revisions of the Questionnaire Items}

Two senior professors revised the item making them computer information technology skill specific. Two male and two female undergraduate Information Systems majors provided feedback on wording, clarity, and order of appearance of the revised items. Based on student feedback, minor changes were made.

\section{Subjects}

Students enrolled in seven computer-related classes in the Information Systems and Operations Management Department at a large Midwestern university participated in the study. Students enrolled in the classes were required to use two or more of the following tools: Word, PowerPoint, Excel, Access, Visio, Project, Visual Basic for Applications (VBA), Microsoft Windows Server 20012, Microsoft SQL Server 2012, and the Web/Internet. The revised instrument was created using Qualtrics, and responses were scored using a 6-point Likert-type scale, from 1 (not at all like me) to 6 (just like me). A total of 304 students participated in the survey, producing 291 useable responses. Twenty-five students (8.6\%) did not indicate a gender, 167 were male (57.4\%), and 99 were female (34\%) students. In terms of age, $23 \%$ were 18 years old, $31.6 \%$ were 19 years old, $14.8 \%$ were 20 years old, $13.4 \%$ were 21 years old, and $8.9 \%$ were 22 years or older. A majority of students identified themselves as White $(90.4 \%)$. Based 


\section{Issues in Information Systems}

Volume 18, Issue 3, pp. 129-140, 2017

upon academic classification, approximately $17 \%$ were seniors, $18.9 \%$ were juniors, $13.1 \%$ were sophomores, and $50.5 \%$ were freshmen. Department enrollments indicated $90 \%$ from the College of Business, $5.8 \%$ from the Applied Science and Technology College, 3.4\% from the College of Sciences and Humanities, and .8\% from Fine Arts.

\section{Data Collection Procedures}

Data were collected in the last week of the 2015 fall semester. Consent to collect data was obtained from the University and each professor who taught the course. Students were invited to complete the Qualtrics online survey posted on Blackboard. The online survey detailed the purpose of the study, the voluntary nature of participation, and the anonymity of responses. Student consent was required to complete the revised motivation survey. At the beginning of the 2016 spring semester, students' grades were collected from each professor.

\section{Analysis Approach}

Exploratory factor analysis (EFA) using principal components factor extraction was used to determine if the items in the Motivation section and those in the Learning Strategies section corresponded to the respective scales. To ensure that it was appropriate to perform factor analysis on the data, a measure of sample adequacy (MSA) statistics was calculated prior to performing the factor analysis (Hair, Black, Babin, \& Anderson, 2010). Validity refers to the degree of adequacy and appropriateness of the interpretations and actions based on the observed scores (Hair et al., 2010; Kane 2001). In this study, confirmatory factor analysis (CFA) was used to investigate the internal validity. A path model was used as a basis for testing convergent validity and discriminant validity. Both convergent and discriminant evidence are fundamental in test validation (Hair et al., 2010), and both are considered subcategories of construct validity. Discriminant validity demonstrated that measures that should not be related are in reality not related. Following the factor analyses, the internal consistency of reliability was computed using Cronbach's coefficient alphas (Cronbach \& Shavelson, 2004). Principle Component Regression was conducted to examine the relationships between motivation and course grade and the use of learning strategies and course grade.

\section{FINDINGS}

This section reports the findings of the MSA, EFA, CFA, and the relationships between grades and different scales in the MSLQ. The data collected for the Motivation section and the data collected for the Learning Strategies section were analyzed separately, and the findings are reported in following separate sections.

\section{Motivation Section: Exploratory Factor Analysis}

The data was subjected to a MSA prior to the EFA. The overall KMO (MSA) statistic was .874, and all item MSAs exceeded the desired value of .7; therefore, the MSA criteria was satisfied. The EFA result showed that all but item 1 had a communality value of .434 and item 22 had a communality value of .451. Communality values were the variance explained for each item. A low communality suggests that the factor model was not working well for that indicator, and a communality of .5 was desired. Seven factors were extracted which accounted for $60.932 \%$ of variance. The factor loadings did not correspond well to the original Motivation scales. With the exception of Test Anxiety. Items in Task Value scale (items 4, 10, 23) were loaded with items in Control Belief (items 2 and 18) and Intrinsic Goal (item 1). Cross loading occurs when a variable had two or more significant factor loadings in an EFA. Although Effort Regulation items were loaded in the same factor, some of the items were also cross-loaded in multiple factors. For example, item 13 (Extrinsic Goal Orientation) was cross-loaded in factors 1 and 6, and item 9 (Control Belief) was cross-loaded in factors 1,3 , and 6 . Six items in various scales were cross-loaded in three different factors.

Several iterations of EFA were conducted to refine the Motivation scales. In general, items with a MSA of lower than .5 are removed. With a sample size of 350 or greater, a loading of .30 was consider significant (Hair et al., 2010). Items with significant cross loadings were deleted. The final Motivation scales consisted of 20 items and 4 scales. Table 1 shows the factor loading. Both Test Anxiety scale and Task Value scale maintain its original items. The eight items in Self-efficacy scale were loaded in two different factors, and one of the items from Control Belief scale was 
loaded with four items $(5,12,15$, and 29) from Self-efficacy. After examining the statements in MSLQ, a decision was made to rename Factor 4, 'Expectancy.'

Table 1. Final Motivation Factor Loadings

\begin{tabular}{|c|c|c|c|c|c|}
\hline \multirow[b]{2}{*}{ Item } & \multicolumn{2}{|c|}{ Factor } & \multirow[b]{2}{*}{ Item } & \multicolumn{2}{|c|}{ Factor } \\
\hline & 1 & 2 & & 3 & 4 \\
\hline M23_TV & .884 & & M5_SE & .879 & \\
\hline M27_TV & .862 & & M31_SE & .862 & \\
\hline M26_TV & .805 & & M21_SE & .862 & \\
\hline M17_TV & .778 & & M20_SE & .702 & \\
\hline$\overline{\mathrm{M} 4 \_\mathrm{TV}}$ & .676 & & M6_SE & & .929 \\
\hline M10_TV & .652 & & M15_SE & & .921 \\
\hline M28_TA & & .825 & M18_CB & & .551 \\
\hline M19_TA & & .821 & M29_SE & & .533 \\
\hline M3_TA & & .756 & M12_SE & & .450 \\
\hline M8_TA & & .753 & & & \\
\hline M14_TA & & .674 & & & \\
\hline
\end{tabular}

\section{Motivation Section: Confirmatory Factor Analysis}

A path model was created based on the four scales resulted from the EFA. According to Hair et al. (2010), the characteristics of a good fit include a CFI of above .90, a GFI of above .90 , and a RMSEA of below .07. The GFI for this model was .864, the CFI was .899, and the RMSEA was .076; therefore, the fit of the model was very close to the satisfying fit criteria. A convergent validity test, then, was conducted. Convergent validity shows items in the same motivation scale were correlated. There were two tests for convergent validity. The first was to test if the unstandardized regression weights (path coefficients) were statistically significant. The second was to test if the factor loadings (standardized regression weights) were .5 or higher. For the Motivation scales, both convergent validity tests were satisfied with all path coefficients being statistically significant and all items had satisfactory factor loadings of higher than .5.

To test discriminant validity, the comparison of root average variance explained and inter-scale correlation was produced for the model. As shown in Table 2, all motivation scales exhibited discriminant validity.

Table 2. Comparison of the Root Average Variance Explained and Inter-Scale Correlation for Motivation Scales

\begin{tabular}{l|c|c|c|c} 
& Expectancy & Task Value & Text Anxiety & Self-efficacy \\
\hline Expectancy & 0.768 & & & \\
\hline Task Value & 0.576 & 0.727 & & \\
\hline Text Anxiety & -0.176 & 0.029 & 0.699 & \\
\hline Self-efficacy & 0.695 & 0.701 & -0.041 & 0.709
\end{tabular}

\section{Motivation Section: Reliability}

Cronbach's Alpha was calculated for each of the scales. All Cronbach's Alpha met the desired .7: Expectancy (.852), Task Value (.869), Test Anxiety (.825), and Self-efficacy (.835), Task Value (.817).

\section{Learning Strategies Section: Exploratory Factor Analysis}

The overall KMO (MSA) statistic was .880, and only two item had MSA of $<$.7. Item 2 had .691 and item 9 had .693, both were approaching the desired .7. The EFA has an overall KMO (MSA) of .880, and two item MSAs did not reach the desired value of .7: item 9 (.693) and item 49 (.699). The EFA result showed that six items did not exceed the 


\section{Issues in Information Systems}

Volume 18, Issue 3, pp. 129-140, 2017

desired communality of .5: item 3 (.417), item 5 (.408), item 9 (.440), item 18 (.493), item 22 (.483), item 29 (.453), and item 3 (.486). The factors accounted for $54.303 \%$ of the variance. Items 3,31 , and 5 did not have significant loading (>.4) on any factor. Item 19 and item 32 were cross-loaded on two factors. The factor loadings did not correspond to the original Learning Strategies scales. Each factor had items loaded from multiple original scales.

The same processes were used to refine the Learning Strategies scales. The communalities loadings for many items were $<.5$, items that had a loading of $>.4$ were retained. The Learning Strategies scales consisted of 29 items and 5 scales. Table 3 shows the factor loading. After carefully analyzing each question in every factor, it was decided to rename Factor 1 as 'Higher-Order Learning,' Factor 2 as 'Self-Governance,' Factor 3 as 'Strategic Thinking,' Factor 4 as "Productivity Strategies,' and Factor 5 as 'Collaborative Learning.'

Table 3. Learning Strategies Factor Loadings

\begin{tabular}{|c|c|c|c|c|c|c|}
\hline \multirow[b]{2}{*}{ Item } & \multicolumn{2}{|c|}{ Factors } & \multirow[b]{2}{*}{ Item } & \multicolumn{3}{|c|}{ Factors } \\
\hline & 1 & 2 & & 3 & 4 & 5 \\
\hline L35_CT & .786 & & L10_Meta & .660 & & \\
\hline L27_Rhrsl & .781 & & L28 Rhrsl & .648 & & \\
\hline L24_Meta & .739 & & L38_Elb & .605 & & \\
\hline L20_CR & .728 & & L50_Elb & .598 & & \\
\hline L41_Rhrsl & .700 & & L43_ER & .579 & & \\
\hline L16_C & .682 & & L40_CT & .550 & & \\
\hline L36_Elb & .675 & & L45_Meta & .534 & & \\
\hline L49r_Time & & .743 & L34_Time & & .745 & \\
\hline L2r_Meta & & .672 & L12 Time & & .675 & \\
\hline L46r_Time & & .663 & L4_Time & & .644 & \\
\hline L6r_ER & & .654 & L1_Org & & .542 & \\
\hline L21r_Time & & .600 & L47_Meta & & .505 & \\
\hline L29r_ER & & .568 & L14_PeerL & & & .742 \\
\hline L26r_Meta & & .557 & L44_Help & & & .712 \\
\hline & & & L37_Help & & & .708 \\
\hline
\end{tabular}

\section{Learning Strategies Section: Confirmatory Factor Analysis}

A path model was created based on the five scales resulted from the EFA. With this initial path model, item 43 had a Standardized Regression Weight of .419 and the factor with item 43 did not exhibit discriminant validity because its root average variance explained was smaller than the correlation with another factor. Item 40 was also removed due to its low communalities loadings in EFA. The final model consisted of 27 items and 5 scales. The GFI for this model was .866, the CFI was .877, and the RMSEA was .059. For Learning Strategies, both GFI and CIF were close to the designed .9, and the RMSEA was below the desired .07. The Learning Strategies scales satisfied both convergent validity tests with all path coefficients being statistically significant and all items had satisfactory factor loadings of higher than .5. In addition, all five scales exhibited discriminant validity.

Table 4. Final Learning Strategies Scales Root Average Variance Comparison and Inter-Scale Correlation

\begin{tabular}{l|c|c|r|r|r} 
& $\begin{array}{c}\text { Productivity } \\
\text { Strategies }\end{array}$ & $\begin{array}{c}\text { Higher-Order } \\
\text { Organization }\end{array}$ & $\begin{array}{c}\text { Self- } \\
\text { Governance }\end{array}$ & $\begin{array}{c}\text { Strategic } \\
\text { Thinking }\end{array}$ & $\begin{array}{c}\text { Collaborative } \\
\text { Learning }\end{array}$ \\
\hline Productivity Strategies & 0.601 & & & & \\
\hline Higher-Order Organization & 0.518 & 0.730 & & & \\
\hline Self-Governance & 0.194 & -0.225 & 0.576 & & \\
\hline Strategic Thinking & 0.593 & 0.574 & 0.115 & 0.606 & \\
\hline Collaborative Learning & 0.447 & 0.498 & -0.184 & 0.563 & 0.653
\end{tabular}




\section{Learning Strategies Section: Reliability}

Cronbach's Alpha was calculated for each of the scales. All but one scale met the desired .7: Collaborative Learning (.688), Self-Governance (.775), Higher-Order Organization (.888), Self-Governance (.741), and Productivity Strategies (.738).

\section{Motivation Scales with Grade}

When EFA was performed to extract factors in the Motivation, factor scores where saved as variables, and these variables were used as independent variables with grade as dependent variable in the regression analysis. With all variables entered into the regression analysis, it showed an Adjusted R Square $\left(\mathrm{r}^{2}\right)$ of .177 and the $F$ ratio was statistically significant at the .001 level. As indicated in Table 5, Test Anxiety did not predict course grade.

Table 5. Regression with Grade as the Dependent Variable and All Motivation Independent Variables

\begin{tabular}{l|c|c|c|r|r} 
& \multicolumn{6}{|c|}{ Unstandardized Coefficients } & Standardized Coefficients & \multicolumn{1}{c|}{$\boldsymbol{~}$ Sig. } \\
\cline { 2 - 7 } & Beta & Std. Error & Beta & & \\
\hline (Constant) & 3.225 & .037 & & 85.998 & .000 \\
\hline Test Anxiety & .017 & .047 & .024 & .350 & .726 \\
\hline Task Value & .087 & .038 & .124 & 2.272 & .024 \\
\hline Self-efficacy & -.319 & .048 & -.453 & -6.714 & .000 \\
\hline Expectancy & .091 & .047 & .129 & 1.921 & .056
\end{tabular}

Since the Beta coefficients provide a guide to the relative importance of the independent variables included in the equation (Hair et al., 2010), a decision was made to exclude variables that had a Beta value of $<.1$ from the equation. The reduced set of analyses included the dependent variable course grade and independent variable Task Value, Selfefficacy, and Expectancy. The regression analysis showed an Adjusted R Square $\left(\mathrm{r}^{2}\right)$ of .188 and an analysis of variance (ANOVA) revealed the $F$ ratio was statistically significant at the .001 level. When the independent variables that had a Beta value of less than .1 were not included in the regression equation, Self-efficacy predicted course grade at the .001 level, and Task Value and Expectancy predicted course grade at the .05 level, as shown in Table 6 .

Table 6. Regression with Grade as the Dependent Variable and All Motivation Independent Variables

\begin{tabular}{l|c|c|c|c|c} 
& \multicolumn{2}{|c|}{ Unstandardized Coefficients } & Standardized Coefficients & $\boldsymbol{t}$ & Sig. \\
\hline & Beta & Std. Error & Beta & & \\
\hline (Constant) & 3.225 & .037 & & 86.130 & .000 \\
\hline Self-efficacy & -.314 & .045 & -.445 & -7.010 & .000 \\
\hline Task Value & .088 & .038 & .125 & 2.304 & .022 \\
\hline Expectancy & .097 & .044 & .138 & 2.213 & .028
\end{tabular}

With a Self-efficacy Beta value of .453 and the standard deviation of the dependent variable (Grade) as .70516, each one-point increase on a 6-point Likert scale on the MSLQ Self-efficacy subscale explained .319 point decrease on the course grade $(-.453 * .70516)$, which is close to one-third of a letter grade.

\section{Learning Strategies Scales with Grade}

As in the regression analysis of Motivation scales and course grade, factor scores where saved in the Learning Strategies EFA as variables, and these variables were used as independent variables with grade as dependent variable in the regression analysis. With all variables entered into the regression analysis, it showed an Adjusted R Square $\left(\mathrm{r}^{2}\right)$ of .133 and an ANOVA revealed an $F$ ratio that was statistically significant at the .001 level. Table 7 lists the regression coefficients. 
Table 7. Regression with Grade as the Dependent Variable and All Learning Strategies Independent Variables

\begin{tabular}{|c|c|c|c|c|c|}
\hline & \multicolumn{2}{|c|}{ Unstandardized Coefficients } & \multirow{2}{*}{$\frac{\text { Standardized Coefficients }}{\text { Beta }}$} & \multirow[t]{2}{*}{$t$} & \multirow[t]{2}{*}{ Sig. } \\
\hline & Beta & Std. Error & & & \\
\hline (Constant) & 3.225 & .038 & & 83.786 & .000 \\
\hline Strategic Thinking & .082 & .039 & .116 & 2.115 & .035 \\
\hline Higher-Order Organization & -.237 & .039 & -.335 & -6.136 & .000 \\
\hline Self-Governance & -.040 & .039 & -.057 & -1.049 & .295 \\
\hline Productivity Strategies & -.083 & .039 & -.118 & -2.160 & .032 \\
\hline Collaborative Learning & .050 & .039 & .070 & 1.284 & .200 \\
\hline
\end{tabular}

As in the regression analysis of Motivation scales, variables that had beta value of $<.1$ and none significant were excluded from the equation. The reduced set of analysis included the dependent variable course grade and independent variables Strategic Thinking, Higher-Order Organization, and Self-Governance. The regression showed an Adjusted R Square $\left(\mathrm{r}^{2}\right)$ of .131 and ANOVA revealed a significant $F$ at .001 level. Table 8 lists the regression coefficients.

Table 8. Regression with Grade as the Dependent Variable and Selected Learning Strategies Independent Variables

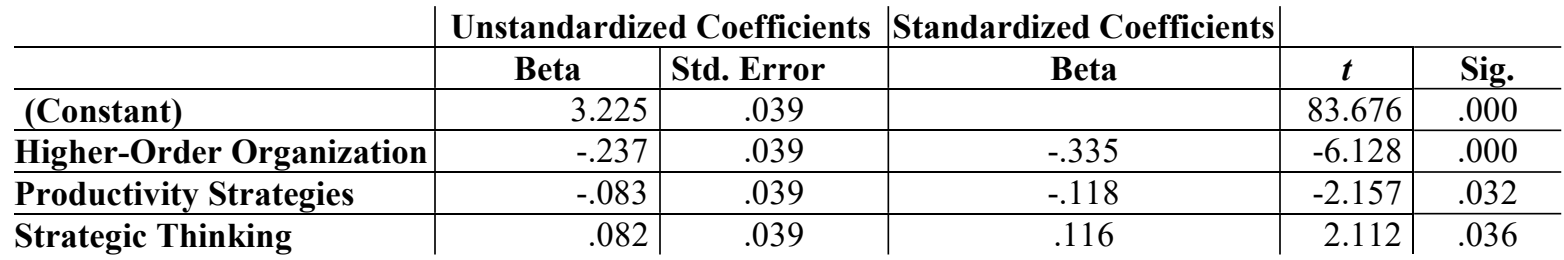

With a negative Beta value of Higher-Order Organization, each one-point increase on a 6-point Likert scale on the MSLQ Higher-Order Organization subscale explained .236 point decrease on the course grade $(-.335 * .70516)$. This was consistent with prior findings (Chalupa, Chen, \& Charles, 2001; Niemczyk \& Savenye, 2001).

To evaluate the variant for the assumptions of regression analysis, residuals were used (Hair et al., 2010) and a normal probability plot of the residuals was generated to provide a visual examination. Figure 1 illustrates the plot for the Motivation analysis and Figure 2 illustrates the plot for the Learning Strategies regression analysis. As shown in these two figures, the plotted values fell fairly close along the diagonal line, which indicated that the residuals were considered to represent a normal distribution; therefore, the regression variant met the assumption of normality.

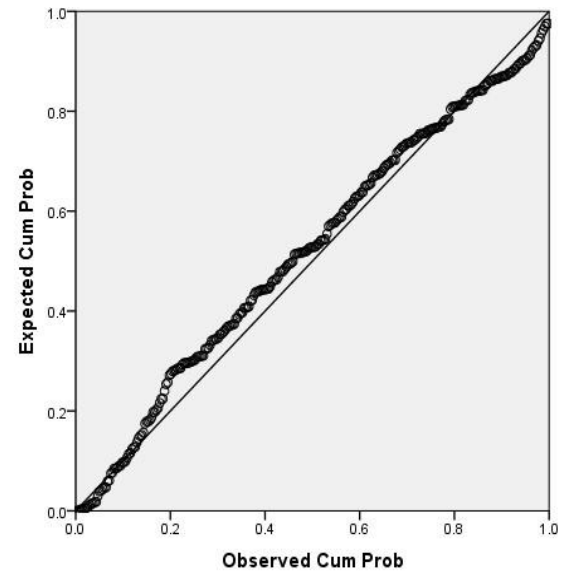

Figure 1. Normal Probability Plot-Motivation

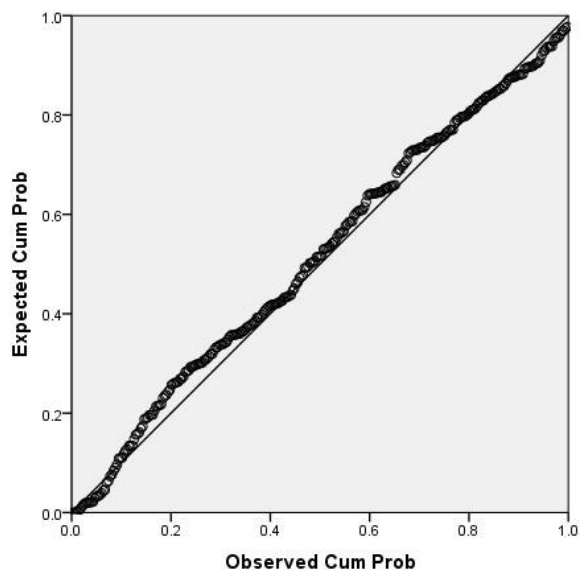

Figure 2. Normal Probability Plot—Learning Strategies 


\section{DISCUSSION}

The EFA and CFA revealed that a modified four-factor model had a better fit to the data than the original five-factor Motivation model. This modified model consisted of a new Expectancy scale and three original scales: Task Value, Test Anxiety, and Self-efficacy. For Learning Strategies section, a modified five-factor model had a better fit than the original nine-factor model. Many of the items did not load into their original Learning Strategies scales, and new names were created for the scales: Productivity Strategies, Higher-Order Organization, Self-Governance, Strategic Thinking, and Collaborative Learning. One interesting finding was that all reverse-coded items $(2,6,21,26,29,46$, and 49) were loaded into the same factor, although they were not from the same scales in the original MSLQ. Rao and Sachs (1999) found reverse-coded items were cluster in the same factor in their study as well. They suggested that the respondents might have trouble answering the reverse-coded statements. Based on measurement theory, Dunn et al. (2012) removed all reverse-coded items before their analyses. Prior research and the findings of this current study suggested that the reverse-coded items should either be reworded or eliminated in future search.

This study found that self-efficacy had a negative effect on grade, as much as one-third of a letter grade. This finding contradicted with prior research conducted in physics (Lynch, 2010) and science classes (Bīrcan \& Sungur, 2016). Since today's college students grew up using basic computer technologies, it might be possible that when students possess a high degree of self-efficacy about their computer information skills, their effort was minimal resulting in a lower grade. Although the prediction of task value and expectancy on better grades was statistically significant, the practical significant was negligible, with a .089 and a .095 increase respectively on a 4-point grade scale. This study also revealed a negative prediction of grade from Higher-Order Organization. Three of the items in this newly renamed scale was in the Critical Thinking scales in the original MSLQ. In the study conducted by Chalupa, Chen, and Charles (2001), Critical Thinking had an inverse relationship with course grade. In Chen's (2002) study, the Learning Strategies section of the MSLQ was used to investigate the relationship between learning strategies and achievement. A positive relationship between effort regulation and paper-and-pencil test score was found, but the relationship between learning strategies and lab assignments (hands-on exercises with the use of computers) was inconclusive because a normal probability plot indicated that the data collected did not meet the assumption of normality. Figure 3 shows the plot adopted from Chen's Study. The comparison of the plot in Figure 2 and in Figure 3 reveals an improvement; however, the findings in this study continued to show an illogical inverse relationship between the use of cognitive strategies and course grade. In addition, the current study found that the more students used the newly renamed 'Productivity Strategies,' a slightly lower grade was earned, and the more they used 'Strategic Thinking,' they earned a slightly higher grade. Although these were statistically significant, the grade that they affected (-.083 and .082 respectively on a 4-point scale) were negligible, similar to findings in the Motivation section.

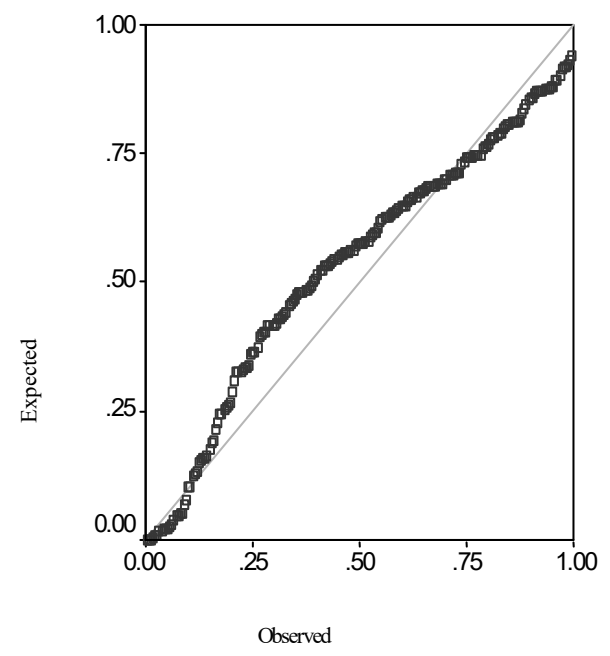

Figure 3. Normal Probability Plot—Lab Assignment (Adopted from Chen, 


\section{Issues in Information Systems}

Volume 18, Issue 3, pp. 129-140, 2017

\section{CONCLUSION}

Further modification of the Motivation for Learning Strategies (MSLQ) explicit to computer information systems courses has practical implications for curriculum development and workplace implementation. However, prior to effective classroom integration, additional item analysis is warranted. Specifically, reverse-coded items require scrutiny considering the motivation and learning strategy characteristics of the current student population. Most notably, results from the modified MSLQ survey extracted from the present study, implied that in order for students to advance their computer information systems academic outcome, educators need to facilitate a process that enables students to resolve their self-efficacy percepts in relationship to scholastic performance; higher self-efficacy resulted in lower grades. Establishment of an authentic motivation and learning strategies research instrument may enable students to attain higher levels of scholastic performance contributing to the closure of the computer information systems employment and skills gap.

\section{REFERENCES}

Auerbach, D. (2016). Where are the grads to fill these in-demand jobs? CareerBuilder. Retrieved from http://www.careerbuilder.com/advice/where-are-the-grads-to-fill-these-indemand-jobs.

Bandura, A. (1986). Social foundation of thought and action: A social cognitive theory. Englewood Cliffs, NJ: Prentice-Hall.

Bandura, A. (1997). Self-efficacy: The Exercise of Control. New York: Freeman.

Bīrcan, H., \& Sungur, S. (2016). The role of motivation and cognitive engagement in science achievement. Science Education International, 27(4).

Bransford, J., Brown, A., \& Cocking, R. (1999). How People Learn: Brain, Mind, Experience, and School. Washington, D.C.: National Academy Press.

Butler, D. (1995). Promoting strategic learning by postsecondary students with learning disabilities. Journal of Learning Disabilities, 25, 226-229.

Butler, D. (1998). A strategic content learning approach to promoting self-regulated learning by students with learning disabilities. In D. Schunk \& B. Zimmerman (Eds.), Self-regulating learning: From teaching to selfreflective practice (pp. 160-183). New York: Guilford Press.

Butler, D. (2002). Individualizing instruction in self-regulated learning. Theory into Practice, 41, 81-92.

Chalupa, M., Chen, C., \& Charles, T. (2001). An analysis of college students' motivation and learning strategies in computer courses: A cognitive view. The Delta Pi Epsilon Journal, 43(4), 185-199.

Chen, C. (2002). Self-regulated learning strategies and achievement in an introduction to information systems course. Information Technology, Learning, and Performance Journal, 20(1), 11-25.

Credé, M., \& Phillips, L. A. (2011). A meta-analytic review of the Motivated Strategies for Learning Questionnaire. Learning and Individual Differences, 21(4), 337-346.

Cronbach, L., J. \& Shavelson, R. J. 2004. "My Current Thoughts on Coefficient Alpha and Successor Procedures." Educational \& Psychological Measurement (64:3), June, pp. 391-418.

Dinsmore, D., Alexander, P., \& Loughlin, S. (2008). Focusing the conceptual lens on metacognition, self-regulation, and self-regulated learning. Educational Psychology Review, 20, 391-409. 
Dunn, K. E., Lo, W. J., Mulvenon, S. W., \& Sutcliffe, R. (2012). Revisiting the motivated strategies for learning questionnaire: A theoretical and statistical reevaluation of the metacognitive self-regulation and effort regulation subscales. Educational and Psychological Measurement, 72(2), 312-331.

Eccles, J. S., Wigfield, A., \& Schiefele, U. (1998) Motivation to succeed. In W. Damon (Series Ed.) \& N. Eisenberg (Vol. E.), Handbook of Child Psychology: Vol. 3. Social, emotional, and personality development (5th ed., pp. 1017-1095). New York: Wiley.

Gottfried, A. E (1990). Academic intrinsic motivation in young elementary school children. Journal of Educational Psychology, 82(3), 525-538.

Hackett, G., \& Betz, N. E. (1989). An exploration of the mathematics Self-efficacy/mathematics performance correspondence. Journal for Research in Mathematics Education, 20, 261-273.

Hair, J. F., Black, W. C., Babin, B. J., \& Anderson, R. E. (2010). Multivariate Data Analysis. ( $7^{\text {th }}$ Ed.). Upper Saddle River, New Jersey: Prentice Hall.

Harris, K., \& Graham, S. (1999). Programmatic intervention research: Illustrations from the evolution of selfregulated strategy development. Learning Disability Quarterly, 22, 251-262.

Hart Research Associates. (2015). Falling short? College learning and career success. Associate of American Colleges and Universities. Retrieved from https://www.aacu.org/leap/public-opinion-research/2015-surveyresults.

Hashemyolia, S., Asmuni, A., Ayub, A. F. M., Daud, S. M., \& Arif, J. (2015). Motivation to use self-regulated learning strategies in learning management system amongst science and social science undergraduates. Asian Social Science, 11(3), 49-56.

Hilpert, J., Stemien, J., van der Hoeven Kraft, K., \& Husman, J. (2013). Evidence for the latent factor structure of the MSLQ: A new conceptualization of an established questionnaire. SAGE Open, 1-10.

Kane, M. (2001). Current concerns in validity theory. Journal of Educational Measurement 38, 319-342.

Lent, R. W., Lopez, F. G., \& Blieschke, K. J. (1993). Predicting mathematics-related choice and success behaviors: Test of an expanded social cognitive model. Journal of Vocational Behavior, 42, 223-236.

Lynch, D. J. (2010). Motivational beliefs and learning strategies as predictors of academic performance in college physics. College Student Journal, 44(4), 920.

National Science Board (2016). Science and Engineer Indicators. National Science Foundation. Retrieved from https://www.nsf.gov/nsb/publications/2016/nsb20161.pdf.

Niemczyk, M. C., \& Savenye, W. C. (2001). The relationship of student motivation and self-regulated learning strategies to performance in an undergraduate computer literacy course. (ERIC Document Reproduction Service No. ED 470107)

Paris, S., \& Paris, A. (2001). Classroom applications of research on self-regulated learning. Educational Psychology, $36,89-101$.

Papantoniou, G., Moraitou, D., Kaldrimidou, M., Plakitsi, K., Filippidou, D., \& Katsadima, E. (2012). Affect and cognitive interference: An examination of their effect on self-regulated learning. Education Research International, 2012.

Pintrich, P. R., \& DeGroot, E. (1990). Motivational and self-regulated learning components of classroom academic performance. Journal of Educational Psychology, 82, 33-40. 


\section{Issues in Information Systems}

Volume 18, Issue 3, pp. 129-140, 2017

Pintrich, P. R., \& Garcia, T. (1991). Student goal orientation and self-regulation in the college classroom. In M. Maehr \& P. R. Pintrich (Eds.), Advances in Motivation and Achievement: Goals and self-regulatory processes, (Vol. 7). Greenwich, CT: JAI Press.

Pintrich, P. R., Smith, D. A. F, Garcia, T., \& McKeachie, W. J. (1991). A Manual for the Use of the Motivated Strategies for Learning Questionnaire (MSLQ). Ann Arbor: University of Michigan, National Center for Research to Improve Secondary Teaching and Learning.

Rao, N., \& Sachs, J. (1999). Confirmatory factor analysis of the Chinese version of the motivated strategies for learning questionnaire. Educational and Psychological Measurement, 59(6), 1016-1029.

Schraw, G., Crippen, K., \& Hartley, K. (2006). Promoting self-regulation in science education: Metacognition as part of a broader perspective on learning. Research in Science Education, 36, 111-139.

Turner, J. C. (1995). The influence of classroom contexts on young children's motivation for literacy. Reading Research Quarterly, 30(3), 410-441.

Zimmerman, B., Bonner, S., \& Kovach, R. (2002). Developing self-regulated learners: Beyond achievement to selfefficacy. Washington, DC: American Psychological Association.

Zimmerman, B., \& Schunk, D. (2001). Self-regulated learning and academic achievement: Theoretical perspectives. Mahwah, NJ: Lawrence Erlbaum Associates.

Zimmerman, B., \& Schunk, D. (2008). Motivation: An essential dimension of self-regulated learning. In D. Schunk \& B. Zimmerman, Motivation and self-regulated learning: Theory, research, and application. Mahwah, NJ: Lawrence Erlbaum Associates. 